\title{
Surveillance of potential associations between occupations and causes of death in Canada, 1965-91
}

\author{
Kristan J Aronson, Geoffrey R Howe, Maureen Carpenter, Martha E Fair
}

\begin{abstract}
Objective-To detect unsuspected associations between workplace situations and specific causes of death in Canada. Methods-An occupational surveillance system was established consisting of a cohort of 457224 men and 242196 women employed between 1965 and 1971, constituting about $10 \%$ of the labour force in Canada at that time. Mortality between 1965 and 1991 has been determined by computerised record linkage with the Canadian mortality database. Through regression analysis, associations between 670 occupations and 70 specific causes of death were measured.
\end{abstract}

Results-There were almost 116000 deaths among men and over 26800 deaths among women. About 28000 comparisons were made between occupations and specific causes of death. With various reporting criteria, several potential associations were highlighted, including: infectious disease mortality among barbers and hairdressers; laryngeal cancer among male metal fitters and assemblers; lung cancer among female waiters; breast cancer among female metal fitters and assemblers; brain cancer among female nursing assistants and male painters; and ischaemic heart disease among female inspectors and foremen and among male taxi drivers and chauffeurs.

Conclusions-When excess risk of mortality is apparent, the intention of this occupational surveillance system is to spark further studies to gain aetiological knowledge.

(Occup Environ Med 1999;56:265-269)

Keywords: epidemiology; occupation; mortality

Division, Occupational and Environmental

Health Research

Section, Statistics

Canada, Ottawa,

Ontario, Canada

M Carpenter

M E Fair

Correspondence to:

Dr Kristan J Aronson,

Community Health and

Epidemiology, Queen's

University, Kingston, ON

K7L 3N6, Canada.

Telephone 0016135456000

ext 4953; fax 001613545

6686; email

aronson@post.queensu.ca

Accepted 12 November 1998

Most advances in the understanding of occupational hazards have been motivated by anecdotal reports of extreme risk in workers (bladder cancer in dye workers, for example), and from the results of analytical studies which have concentrated on specific worker groupsfor example, asbestos workers. The limitation of these approaches is that many occupational hazards may remain undetected because they are not the subject of systematic study. For the vast majority of workplace environments, there is no evidence about hazard one way or the other, and recognised risks may represent only the tip of the iceberg. ${ }^{1}$
Occupational surveillance can be defined as the systematic collection, evaluation, and dissemination of data relating workplace exposures to disease or mortality among workers, with the ultimate aim of reducing or preventing excess risk. ${ }^{2}{ }^{3}$ There have been relatively few surveillance systems established to routinely monitor associations between occupation and mortality risk. Although each surveillance system may have its limitations, they are useful tools in the effort of identifying occupational hazards.

The present study takes advantage of a previously established set of Canadian data and the availability of the computerised record linkage system to the Canadian mortality database to create a surveillance system which can provide valuable information at a relatively low cost. This study is unique in that it has the ability to ascertain subsequent mortality in a large and representative cohort of working Canadians in which occupational information was collected before death. This study has the particular advantage of being able to identify mortality risks among women related to occupation, whereas most previous studies have not included women. Women are increasingly participating in the established labour force - that is, working outside the home-and taking on less traditional and more hazardous employment. ${ }^{4}$ In Canada, women constituted $27 \%$ of the labour force in $1960,37 \%$ in 1976 , and $45 \%$ in $1994 . .^{5}$ Most working women have not been the subject of study, which presented the main limitation to evaluating and controlling occupational hazards for women. ${ }^{67}$

The objectives of this study were to determine the mortality experience of the cohort from 1965 to the end of 1991, thus providing up to 26 years of follow up, and to determine associations between job titles and specific causes of death between 1965 and 1991 for women and men.

\section{Methods}

A unique database was created through the collaboration of University researchers, Employment Canada, and Statistics Canada, with additional funding from Health Canada and the National Cancer Institute of Canada. Essentially, records from employment surveys of about $10 \%$ of the Canadian labour force between 1965 and 1971 were linked with records on deaths which occurred from 1965 to 1991 among the people identified in the surveys.

This report is based on information for 457224 men and 242196 women working in 
Canada during the time that employment surveys were conducted each year in 1965-9 and 1971 (data for 1970 were destroyed inadvertently many years ago). Occupations reported were coded into standardised Canadian occupational codes with 1961 codes for those surveyed in 1965-9 and into 1971 codes for those surveyed in 1971, and these two coding groups were analysed separately. For the purposes of this report, occupations were divided into two socioeconomic groups, professional and semiprofessional workers (white collar), and non-professional workers (blue collar). ${ }^{8}$ Exposure is defined as employment in a particular occupation for at least 1 year.

To identify those who had died, this occupational cohort was linked to the Canadian mortality database with well established probabilistic record linkage methods ${ }^{9}$ and the several personal identifiers available in both databases, including first name, middle name, surname, complete date of birth, sex, and social insurance number. For subjects identified as having died between 1965 and the end of 1991, the international classification of diseases (ICD) code for the underlying cause of death was obtained from death registrations. Codes for the three ICD versions used over this period were converted into the 70 classifications for cause of death used in this study, investigated relative to about 670 occupational titles. Those not identified as dead were assumed to be alive, as it is established that only about $4 \%$ of deaths of residents of Canada are not recorded in the Canadian mortality database. ${ }^{10}$

Person-years were calculated from entry into the cohort until the time of death, or to the end of 1991 if no death occurred. Relative risks (RRs) and associated 95\% confidence intervals (95\% CIs) were determined with separate Poisson regression models for each comparison between occupation and cause of death, with control for age and calendar periods in 5 year groups. ${ }^{11}$ The AMFIT package within EPICURE $^{12}$ produced the maximum likelihood estimate of $R R$, and tests of significance and $95 \%$ CIs around the RR were estimated with the likelihood ratio method. ${ }^{13}$ In the results $\mathrm{p}$ values refer to the log likelihood ratio statistic $p$ value for each fit of the regression model, a test to determine if the occupation is significantly associated with the cause of death. All comparisons were made between one occupation and all occupations within the same occupational class only (white or blue collar, respectively) - that is, the mortality for each specific cause in one occupation was compared with that in all occupations within the same occupational class, and the ratio of the rates is expressed as the RR. Analyses were conducted separately for men and women and white and blue collar jobs, and within each, two age at death groups (all ages, and its subset of up to age 64) were considered.

Due to the nature of occupational surveillance - that is, investigating many occupations and many causes of death-thousands of comparisons have been made in this analysis. Caution should be exercised in interpreting significant RRs as meaning that the true $R R$ is not equal to 1.0. Several hundred RRs would be expected to be significant at least at the $p<0.05$ level, simply due to chance alone. This hypothesis generating approach is intentional and warranted because new potential associations are being sought which may otherwise not be the subject of study. Testing these potential associations in other analytical studies is necessary to determine causality, and therefore interpretation of results and reference to other studies is not attempted here.

With thousands of results available, it is possible to highlight only a few here, and these have been selected according to various criteria specified in the tables and results section. To avoid publication bias, all results with no selection will be available on CD-ROM from Statistics Canada in $1999 .{ }^{14}$

ETHICAL ISSUES

This work was approved by the Registrar General in each province and by Statistics Canada for permission to conduct record linkage with the Canadian mortality database. Approval was also given by a human ethics review committee at the Office of Research Services, University of Toronto, and by the human ethics committee, Faculty of Health Sciences, Queen's University. The confidentiality of people has been protected throughout the creation and use of this database. Before researchers can handle the data, all names are excluded. People are identified only by a Statistics Canada identification number which cannot be linked to other databases. Personal identifiers were kept under security regulations by Statistics Canada and were not available to researchers. No person was contacted and it is not possible to identify any person in any computer file or report.

PREVIOUS ANALYSES

The mortality experience of this cohort has been determined previously through two computerised record linkages to the Canadian mortality database: the first linkage covered deaths to the end of 1973 and the mortality results among men were published ${ }^{15}$; and the second linkage determined mortality to the end of 1979, and results for cancer mortality among men were published. ${ }^{16}$ The smaller size of the group of women and their relatively young age prohibited meaningful analysis until now. ${ }^{7}$

\section{Results}

Average duration of follow up was 26 years, with men contributing over 11 million personyears and women contributing more than 6 million. Among the 457224 men, there were almost 116000 deaths, and over 26800 deaths among the 242196 women. The statistical analysis produced about 28000 comparisons between occupations and specific causes of death (there was no death for several combinations of occupation and cause of death).

Table 1 shows the 15 results for the comparisons between occupations and causes of death which met the following very stringent reporting criteria: $\geqslant 5$ deaths, $R R>1.50$, and $p$ value $<0.0001$. Making the selection according 
Table 1 Fifteen potential associations between causes of death and occupations which meet the criteria of $\geqslant 5$ deaths, relative risk $>1.50$, and $p$ value $<0.0001$

\begin{tabular}{|c|c|c|c|c|c|c|c|}
\hline Cause of death & Occupation & Sex & Age group & Person-years & Deaths & Relative risk & $95 \% C I$ \\
\hline Infectious diseases & Barbers, hairdressers, manicurists (B) & $M$ & All & 26954 & 9 & 7.31 & 3.78 to 14.15 \\
\hline \multirow[t]{2}{*}{ Laryngeal cancer } & Maids and related service workers (B) & $\mathrm{F}$ & All & 164071 & 9 & 7.79 & 3.56 to 17.05 \\
\hline & Metal fitters and assemblers (B) & M & $\leqslant 64$ & 81420 & 11 & 4.85 & 2.65 to 8.89 \\
\hline Lung cancer & Waiters (B) & $\mathrm{F}$ & All & 340391 & 144 & 1.74 & 1.47 to 2.07 \\
\hline Other cancer & Waiters (B) & $\mathrm{M}$ & All & 73726 & 49 & 2.54 & 1.91 to 3.37 \\
\hline \multirow[t]{2}{*}{ Ischaemic heart disease } & Inspectors and foremen (W) & $\mathrm{F}$ & All & 3331 & 15 & 3.94 & 2.36 to 6.59 \\
\hline & Taxi drivers and chauffeurs (B) & M & All & 27693 & 160 & 1.61 & 1.38 to 1.89 \\
\hline Pneumonia & Guards, watchmen (B) & M & All & 86803 & 113 & 1.54 & 1.27 to 1.87 \\
\hline \multirow[t]{2}{*}{ Motor vehicle accidents } & Lorry drivers (B) & M & $\leqslant 64$ & 343600 & 155 & 1.52 & 1.29 to 1.79 \\
\hline & Lumbermen (B) & M & All & 182111 & 130 & 2.23 & 1.87 to 2.66 \\
\hline \multirow[t]{5}{*}{ Other accidents } & Air pilots, navigators and flight engineers (W) & $\mathrm{M}$ & All & 4623 & 9 & 10.90 & 5.61 to 21.16 \\
\hline & General foremen, construction (W) & $\mathrm{M}$ & All & 57340 & 35 & 2.48 & 1.76 to 3.51 \\
\hline & Lumbermen (B) & $M$ & All & 182111 & 164 & 2.49 & 2.13 to 2.91 \\
\hline & Fishermen $(\mathrm{B})$ & M & All & 77380 & 71 & 2.17 & 1.72 to 2.75 \\
\hline & Miners (B) & M & All & 85326 & 81 & 2.47 & 1.98 to 3.09 \\
\hline
\end{tabular}

$\mathrm{B}=$ blue collar; $\mathrm{W}=$ white collar.

Table 2 Potential associations between causes of death and occupations which meet the criteria of $\geqslant 5$ deaths, relative risk $>5.00$, and $p$ value $<0.05$ (excluding those in table 1)

\begin{tabular}{|c|c|c|c|c|c|c|c|}
\hline Cause of death & Occupation & Sex & Age group & Person-years & Deaths & Relative risk & $95 \% C I$ \\
\hline Oesophageal cancer & Beverage processors (B) & M & All & 10404 & 5 & 5.99 & 2.49 to 14.45 \\
\hline Laryngeal cancer & Stenographers (B) & $\mathrm{F}$ & $\leqslant 64$ & 460245 & 5 & 6.91 & 2.25 to 21.28 \\
\hline Bile duct cancer & $\begin{array}{l}\text { Operators of earth moving and other construction } \\
\text { machinery (B) }\end{array}$ & M & $\leqslant 64$ & 79185 & 5 & 5.49 & 2.22 to 13.56 \\
\hline Pancreatic cancer & Government administrators (W) & M & All & 3760 & 5 & 6.00 & 2.48 to 14.53 \\
\hline Lip cancer & $\begin{array}{l}\text { Labourers, excluding those engaged in agriculture, } \\
\text { fishing, logging or mining (B) }\end{array}$ & M & $\leqslant 64$ & 1760000 & 5 & 5.87 & 1.58 to 21.89 \\
\hline Chronic myeloid leukaemia & Foremen (W) & M & $\leqslant 64$ & 190770 & 5 & 5.10 & 1.60 to 16.27 \\
\hline \multirow[t]{2}{*}{ Other leukaemia } & Purchasing agents and buyers (W) & $M$ & All & 27624 & 5 & 5.90 & 2.35 to 14.82 \\
\hline & Construction workers (B) & $\mathrm{M}$ & All & 29884 & 5 & 5.66 & 2.34 to 13.71 \\
\hline Other cancer & Funeral directors and embalmers (W) & M & All & 4187 & 5 & 6.00 & 2.48 to 14.47 \\
\hline Ischaemic heart disease & Inspectors and foremen (W) & $\mathrm{F}$ & $\leqslant 64$ & 2844 & 6 & 7.10 & 3.13 to 16.13 \\
\hline Influenza & Clerical occupations (B) & $\mathrm{F}$ & $\leqslant 64$ & 830547 & 5 & 9.28 & 2.22 to 38.87 \\
\hline Non-alcohol cirrhosis & Paper makers (B) & M & All & 7725 & 5 & 5.98 & 2.48 to 14.40 \\
\hline Nephritis & Owners and managers (W) & $\mathrm{F}$ & $\leqslant 64$ & 42424 & 5 & 10.45 & 2.38 to 45.89 \\
\hline Motor vehicle accidents & Rolling mill operators (B) & M & $\leqslant 64$ & 4512 & 7 & 5.14 & 2.45 to 10.79 \\
\hline Other accidents & Attendants in doctors' and dentists' offices (W) & $\mathrm{F}$ & $\leqslant 64$ & 20932 & 6 & 5.61 & 2.31 to 13.64 \\
\hline All cancer & Foremen, textile processing occupations (W) & M & $\leqslant 64$ & 834 & 6 & 5.79 & 2.60 to 12.91 \\
\hline
\end{tabular}

$\mathrm{B}=$ blue collar; $\mathrm{W}=$ white collar.

to other arbitrary yet stringent criteria ( $\geqslant 5$ deaths, $R R>5.0$, and $p$ value $<0.05$ ) yields the $16 \mathrm{RRs}$ in table 2 . These results only give a taste of the many potential associations which have been investigated in this surveillance system.

There are at least two other angles from which these results can be viewed-that is, by occupation or by cause of death. As an example of looking at results for a specific occupation, table 3 shows selected results for male lorry drivers. From the angle of cause of death, a leading cause of premature death among women such as breast cancer may be of interest in terms of possible occupational aetiology. ${ }^{17}$ In table 4, the three results are shown for breast cancer mortality and occupations which meet the criteria of $\geqslant 5$ deaths, $R R>1.5$, and $p$ value $<0.05$. Other examples shown in this table and using the same selection criteria are mortality from prostate cancer, brain cancer, and several types of leukaemia. As this cohort is so large

Table 3 Potential associations with the occupation of lorry driver among men of all ages only (person-years $=373018$ ), which meet the criteria of $>5$ deaths, relative risk $\geqslant 1.30$, and $p$ value $<0.05$

\begin{tabular}{lrlll}
\hline Cause of death & Deaths & RR & $95 \%$ CI & $p$ Value \\
\hline Colon cancer & 86 & 1.30 & 1.05 to 1.62 & 0.0215 \\
Laryngeal cancer & 28 & 1.59 & 1.08 to 2.33 & 0.0268 \\
Lung cancer & 467 & 1.36 & 1.24 to 1.49 & $<0.0001$ \\
Diabetes & 64 & 1.39 & 1.08 to 1.79 & 0.0139 \\
Ischaemic heart disease & 1217 & 1.30 & 1.23 to 1.38 & $<0.0001$ \\
Non-alcohol cirrosis & 64 & 1.66 & 1.29 to 2.14 & 0.0003 \\
Motor vehicle accidents & 164 & 1.49 & 1.27 to 1.74 & $<0.0001$ \\
\hline
\end{tabular}

and has been followed up for over 2 decades, it is possible to investigate even quite rare causes of death.

\section{Discussion}

Possible associations between occupational factors and health outcomes, as measured by mortality, have been identified through this analysis of occupational surveillance data. Associations flagged may confirm earlier findings, but more often raise new hypotheses about which there is no earlier evidence. By design, causal inference is not possible with this type of study and further investigations must test the new hypotheses raised here. The data available for this work are essential in monitoring occupational mortality on an ongoing basis.

Strengths include the fact that this system of occupational surveillance relies on occupational information collected before death, whereas most other systems obtain job titles from death certificates. ${ }^{18}$ Further, in comparison with individual studies, one key advantage is the large sample size which affords the ability to assess risk potentially associated with many occupations and causes of death at once.

Although the definition of exposure used here, employment for a single year is likely for many people to represent earlier and future employment for several years, and associations with occupational mortality are often found in people with relatively limited occupational experience, an important issue which may 
Table 4 Potential associations between causes of death and occupations which meet the criteria of $\geqslant 5$ deaths, relative risk $>1.50$, and $p$ value $<0.05$, for seven selected causes of death

\begin{tabular}{|c|c|c|c|c|c|c|c|}
\hline Cause of death & Occupation & Sex & Age group & Person-years & Deaths & $R R$ & $95 \% C I$ \\
\hline \multirow{3}{*}{ Breast cancer } & Secretaries and stenographers (B) & $\mathrm{F}$ & All & 44405 & 23 & 1.83 & 1.21 to 2.75 \\
\hline & Dressmakers and seamstresses (B) & $\mathrm{F}$ & $\leqslant 64$ & 17679 & 14 & 2.02 & 1.19 to 3.42 \\
\hline & Metal fitters and assemblers (B) & $\mathrm{F}$ & $\leqslant 64$ & 15717 & 9 & 2.15 & 1.12 to 4.15 \\
\hline \multirow[t]{7}{*}{ Prostate cancer } & Office managers (W) & M & All & 19658 & 11 & 1.99 & 1.09 to 3.62 \\
\hline & Civil engineers (W) & M & All & 7096 & 5 & 3.94 & 1.63 to 9.52 \\
\hline & Janitors and cleaners (B) & $\mathrm{M}$ & $\leqslant 64$ & 112697 & 16 & 2.15 & 1.30 to 3.57 \\
\hline & Commercial travellers (B) & M & All & 12314 & 7 & 2.40 & 1.14 to 5.05 \\
\hline & Compositors and typesetters (B) & M & All & 34931 & 13 & 1.85 & 1.07 to 3.19 \\
\hline & Warehousemen and freight handlers (B) & M & All & 177205 & 43 & 1.59 & 1.17 to 2.15 \\
\hline & Bottlers, wrappers, labellers (B) & M & All & 64060 & 20 & 1.90 & 1.22 to 2.95 \\
\hline \multirow[t]{4}{*}{ Brain cancer } & Nursing assistants and aides (B) & $\mathrm{F}$ & All & 51725 & 6 & 2.61 & 1.16 to 5.88 \\
\hline & Dressmakers and seamstresses (B) & $\mathrm{F}$ & All & 24024 & 6 & 4.41 & 1.95 to 9.97 \\
\hline & Painters, except construction and maintenance (B) & M & All & 24734 & 6 & 3.79 & 1.70 to 8.48 \\
\hline & Bricklayers, stonemasons, and tile setters (B) & M & $\leqslant 64$ & 40591 & 6 & 2.62 & 1.17 to 5.86 \\
\hline Chronic lymphocytic leukaemia & Sales clerks (B) & $\mathrm{M}$ & All & 272218 & 9 & 2.24 & 1.15 to 4.38 \\
\hline \multirow[t]{2}{*}{ Acute myeloid leukaemia } & Stenographers (B) & $\mathrm{F}$ & $\leqslant 64$ & 460245 & 10 & 2.35 & 1.18 to 4.67 \\
\hline & Warehousemen and freight handlers (B) & $\mathrm{M}$ & All & 177205 & 8 & 2.72 & 1.34 to 5.52 \\
\hline \multirow[t]{2}{*}{ Chronic myeloid leukaemia } & Foremen (W) & M & $\leqslant 64$ & 190770 & 5 & 5.10 & 1.60 to 16.27 \\
\hline & Mechanics and repairmen (B) & M & All & 219281 & 5 & 2.97 & 1.20 to 7.35 \\
\hline \multirow[t]{5}{*}{ Other leukaemia } & Purchasing agents and buyers (W) & $M$ & All & 27624 & 5 & 5.90 & 2.35 to 14.82 \\
\hline & Bookkeepers and cashiers (B) & M & All & 86364 & 6 & 2.93 & 1.30 to 6.58 \\
\hline & Waiters (B) & M & All & 73726 & 6 & 2.79 & 1.25 to 6.27 \\
\hline & Telephone operators (B) & $\mathrm{F}$ & All & 115179 & 6 & 4.02 & 1.75 to 9.24 \\
\hline & Construction workers (B) & M & All & 29884 & 5 & 5.66 & 2.34 to 13.71 \\
\hline
\end{tabular}

$\mathrm{B}=$ blue collar; $\mathrm{W}=$ white collar.

temper the interpretation of these results is the stability of jobs over time. Occupational information was reported by employers at the time of the original surveys, and so these are probably quite reliable. However, we have no information on job titles beyond 1971, the last year of the employment surveys conducted on this cohort. This is typical of occupational cohorts and generally the effect of this potential misclassification is to attenuate the strength of the association. However, the relatively high statistical power of this investigation for many occupations offsets the consequences of potential misclassification (and therefore attenuated RRs) which may occur as outcome assessment occurs often long after exposure assessment.

Actual exposures or measures of exposuresuch as duration and intensity-are not considered here. Before more definitive associations are established between occupation and cause of death, in depth epidemiological studies must be performed to follow up the leads suggested by results from this study. Linkage of job titles to exposures determined by industrial hygienists has been undertaken and results are forthcoming (unpublished data).

In terms of the accuracy and completeness of death information, $\geqslant 95 \%$ of deaths of Canadians are captured in the Canadian mortality database. ${ }^{10}$ However, some of the categories of death used to allow examination of a wide range of causes were broad and possibly masked some important increases in risk which would be apparent in a more specific study of, for example, accidents. This was intended to be a "big picture" study on the potential impact of occupations on causes of death. Finally, it should be remembered that mortality may be a poor indicator of chronic conditions that are not fatal.

Two other limitations are the absence of individual data on potential confounders, and the unavoidable issue of multiple comparisons. Associations between occupations and causes of death may reflect the socioeconomic status-for example, income and educational attainment, etc-of the decedents which, through lifestyle as reflected in confounding factors-such as smoking or alcohol consumption - may be more closely associated with mortality than the occupation themselves. ${ }^{19}$ We have tried to minimise this possible effect by comparing people only within the same occupational class (white or blue collar), although the broad classification into only two groups may not obviate this problem. The advantage of these internal comparisons is that the healthy worker effect is avoided..$^{19}{ }^{20}$ As the primary objective here is to generate hypotheses, issues of confounding may properly be considered in other data sources used to confirm or negate the hypotheses generated by the present study.

This study produced over 26000 occupation, cause specific, sex and age group specific RRs. We caution that the $p$ values of $<0.05$ should not be interpreted in the usual way as nominal values - that is, a less than 1 in 20 chance-because so many comparisons have been made. It is impossible to know which of these are true increased or decreased risks, and which occurred by chance alone. This approach is justified, in our view, by the objective of this work of flagging all potential associations. The usual criterion of significance should be viewed as only one tool in interpreting these data, with results from other studies taken into consideration as well as the biological plausibility of potential associations. More studies must be conducted before a potential association found here is labelled as causal.

Future work with this cohort will include a linkage to determine the cancer incidence, with the National Cancer Incidence Reporting System. Priorities for future research and preventive action related to occupation, cancer incidence, and mortality in Canada will be established at least in part with the information provided through the continued use of this database. 
After measuring these relations, the next step is to conduct specific studies of many of the leads raised here. If findings are confirmed, action can be taken to improve the health of workers who are still exposed to these and other occupational hazards, and to reduce or eliminate exposure to harmful substances and exposure circumstances.

Funding to establish this cohort was originally provided by the National Cancer Institute of Canada through their Epic ogy Unit. Record linkage and analysis was funded by Health Canada through the National Health Research and Development Program (NHRDP), grant number 6606-5027-53. KJA in part through a research scholar award, also from NHRDP, and is now supported through a career scientis award from the Ontario Ministry of Health Special thanks is given to Pierre Lalonde, Russell Wilkins, Lucille Poirier, Sevag Serimazi, and Tanya Weston.

1 Siemiatycki J. Risk factors for cancer in the workplace. Boca Raton: CRC Press, 1991.

2 Langmuir AD. The surveillance of communicable diseases of national importance. N Engl f Med 1963;268:182-92.

3 Baker EL, Honchar PA, Fine LJ. I. Surveillance in occupational illness and injury: concepts and content. Am f Public tional illness and injury: concep

4 Passannanate MRC, Nathanson CA. Women in the labour force: are sex mortality differentials changing?. F Occup Med 1987;29:21-8.

5 Women in Canada: a statistical report. 3rd edition. Ottawa: Statistics Canada Ministry of Industry, 1995. (Cat No 89-503E.)

6 Klitzman S, Silverstein B, Punnett L, et al. A women's occupational health agenda for the 1990s. New Solution 1990;1:7-17.

7 Aronson KJ, Howe GR. Utility of a surveillance system to detect associations between work and cancer among women in Canada, 1965-91. F Occup Med 1994;36:1174-9.
8 Pineo PC. Revisions of the Pineo-Porter-McRoberts socioeconomic classification of occupation for the 1981 census. Hamilton, Ontario: McMaster University, 1985. (QSEP Report No 125.)

9 Smith ME, Newcombe H. Use of the Canadian mortality data base for epidemiological follow up. Can F Public Health 1982;73:39-46.

10 Shannon $\mathrm{H}$, Jamieson $\mathrm{E}$, Walsh $\mathrm{C}$, et al. Comparison of individual follow up and computerized record linkage using the Canadian National Mortality Data Base. Can $\mathcal{F}$ Public Health 1989;80:54-7.

11 Checkoway H, Pearce NE, Crawford-Brown DJ. Research methods in occupational epidemiology. Oxford: Oxford University Press, 1989.

12 EPICURE Software. Seattle, WA: HiroSoft International Corporation, 1993.

13 Breslow NE, Day NE. Statistical methods in cancer research. Volume II. The design and analysis of cohort studies. Lyon: IARC, 1987. (IARC Sci Publ No 82.)

14 Aronson KJ, Howe GR, Carpenter M, et al. Occupational surveillance in Canada: cause-specific mortality among working men and women, 1965-1991. Ottawa: Statistics Canada, 1998 (in press). (CD-ROM Product No 84-546-XCB.)

15 Howe GR, Lindsay JP. A follow up study of a ten-percent sample of the Canadian labour force. I. Cancer mortality in males, 1965-73. F Natl Cancer Inst 1983;70:37-44.

16 Lindsay JP, Stavraky KM, Howe GR. Cancer mortality among males $1965-79$, in a $10 \%$ sample of the Canadian labour force. F Occup Med 1993;35:408-14.

17 Goldberg MS, Labreche F. Occupational risk factors for female breast cancer: a review. Occup Environ Med 1996;53:145-56.

18 Steenland K, Beaumont J. The accuracy of occupation and industry data on death certificates. $\mathcal{F}$ Occup Med 1984;26: 288-96.

19 McMichael AJ. Standardized mortality ratios and the healthy worker effect: scratching beneath the surface. $\mathcal{F}$ Occup Med 1976;18:165-8.

20 Howe GR, Chiarelli AM, Lindsay JP. Components and modifiers of the healthy worker effect: evidence from three occupational cohorts and implications for industrial compensation. Am f Epidemiol 1988;128:1364-75. 